Baxter, D. \& Roy, R. \& Gao, X. "Managing knowledge within the manufacturing enterprise: An overview", International Journal Of Manufacturing Technology Management (in press: accepted October 2008). Volume 18, Number 2, 28 May 2009, pp. 183-209

\title{
Managing knowledge within the manufacturing enterprise: An overview
}

\author{
David Baxter \\ d.baxter@cranfield.ac.uk \\ Decision Engineering Centre, Cranfield University, Cranfield, MK43 0AL, UK \\ Rajkumar Roy \\ r.roy@cranfield.ac.uk \\ Decision Engineering Centre, Cranfield University, Cranfield, MK43 0AL, UK
}

Telephone: 01234755661

Fax: 01234754065

James Gao

j.gao@gre.ac.uk

School of Engineering, University of Greenwich Chatham Maritime, Kent, ME4 4TB, UK

Telephone: 01634883341

Fax: 0163443153 


\section{Managing knowledge within the manufacturing enterprise: An overview}

\section{Abstract}

This paper examines the literature relating to manufacturing knowledge and describes how it contributes to the manufacturing enterprise. The review shows that there is a strong emphasis on design in the manufacturing knowledge research domain, and that detailed design is the main focus for current research. An analysis is carried out according to publication date and consequently trends are identified. The design focus is increasing, and the trends show that the domain is driven by industrial applications. The contribution to fundamental research in areas such as knowledge modelling is increasing. Areas that currently have little work in this domain include conceptual design and service.

Keywords: Literature review, manufacturing knowledge, enterprise integration

\section{Introduction}

Manufacturing in the $21^{\text {st }}$ Century is a major technological challenge that must be tackled on several fronts. Engineering is ever advancing, and products are becoming more highly integrated and complex. The new manufacturing enterprise is knowledge intensive and globally distributed. It must collaborate closely with a range of partners across geographical and technological boundaries. The manufacturing enterprise has been the focus of a significant body of research into the capture, representation, sharing and application of knowledge. This paper aims to characterise manufacturing knowledge research by identifying, classifying and analysing a targeted selection of research papers. This analysis seeks to highlight current trends and identify areas for future research.

Manufacturing is considered from an enterprise perspective (Qiu 2006, Molina \& Bell 1999). The enterprise view encompasses a range of operations within the manufacturing business, including: customer requirements capture, product design, manufacturing engineering, production scheduling and production control. These areas must communicate with one another across the enterprise, and each has its own particular knowledge and information requirements. The development of information and knowledge models to support these activities represents one research stream. A closely related research area is knowledge management, which provides solutions to less specific knowledge and information management challenges such as storing and retrieving information, and finding relevant expertise through documents and personnel. Another related area is intelligent systems (also expert systems and knowledge based engineering), which provide solutions to specific challenges in the manufacturing domain, such as optimising a component for injection moulding or assessing a sheet metal part for manufacturability. 


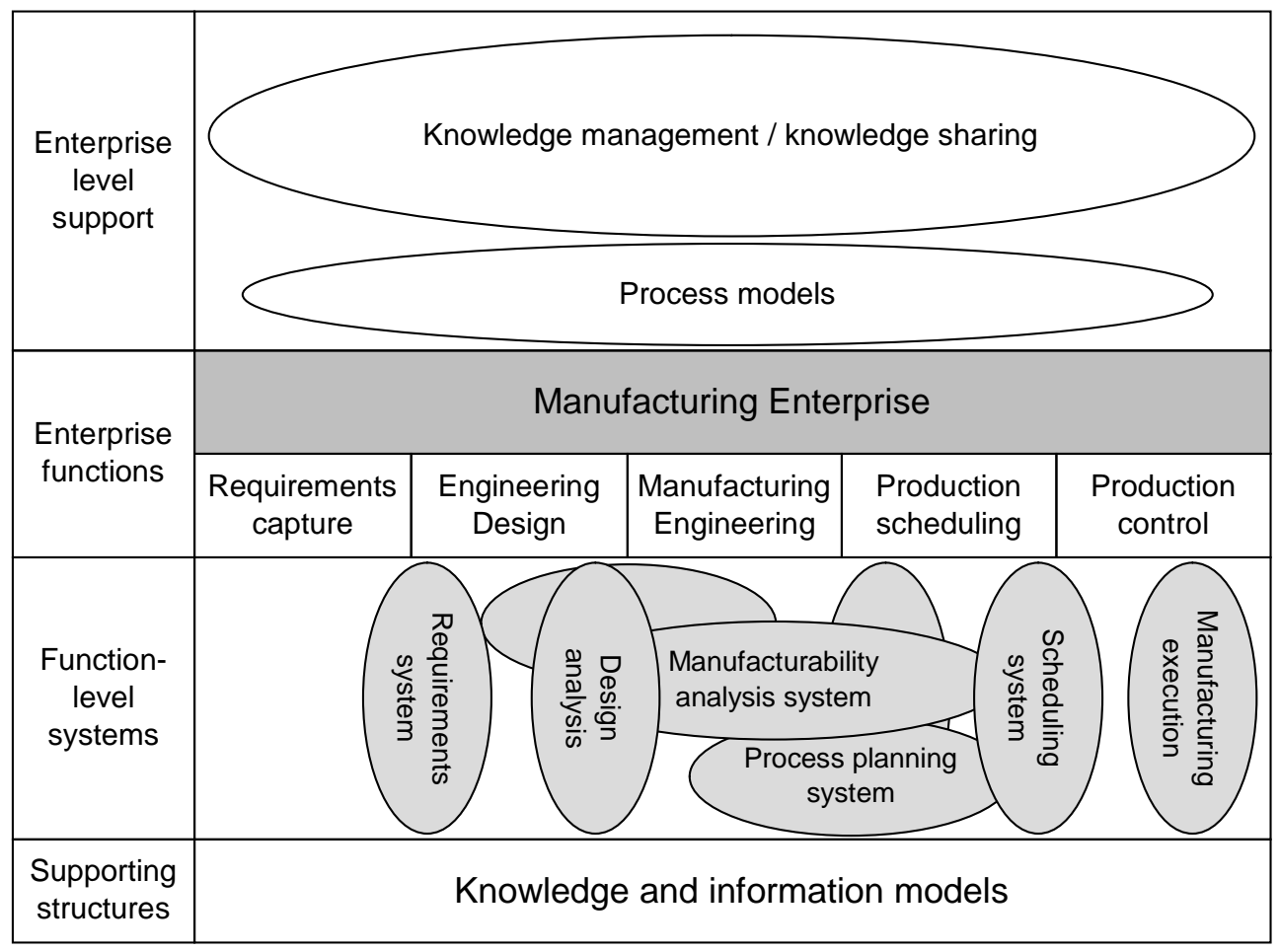

Figure 1: manufacturing knowledge across the enterprise

Figure 1 provides a high level view of manufacturing knowledge systems, tools and supporting structures. The central section of the figure shows a selection of key enterprise functions relating to product development and production. The top section shows enterprise level support: knowledge management and knowledge sharing applications. Process models also provide support at the enterprise level. Two types of function-level systems are shown: vertical methods, which target a specific functional domain, and horizontal methods, which support the integration across two or more domains. An example of a horizontal method is a system to create a manufacturing process plan from a geometric model of a product or component. An example of a vertical method is a system to optimise a production schedule based on current machine loading. At the bottom of the figure, knowledge and information models comprise the supporting structures that form the basis of the function level systems. At this level, the syntax and semantics as well as the structure and relationships between terms are defined. A general objective at this level is to provide structures that support communication across the various enterprise functions. The adoption of standard representations for the various systems at this level supports inter- and intraenterprise communication by ensuring the various partners can understand the content and interface with the various systems.

\section{Research method}

The term "manufacturing knowledge" is not defined in advance. This review paper seeks to develop a description of the domain by finding papers that refer to 'manufacturing knowledge', or 'manufacturing' and 'knowledge'. The inclusion of the words 'manufacturing' and 'knowledge' within the title, abstract or keywords of the research is sufficient for its inclusion in the study (within the limited search space that is defined in the next section). This review provides researchers in the manufacturing domain with a view of the current status of manufacturing knowledge 
from a technology neutral perspective. This offers a broad scope from which to judge the current contribution of research topics relating to manufacturing knowledge. Having identified the papers, they will be described and categorised. The analysis of these categories will provide a view of the structure and content of the manufacturing knowledge domain.

The method for identifying research carried out in manufacturing knowledge will be described in this section. A number of databases were selected, including INSPEC, SCOPUS, ABI/INFORM (ProQuest), Business source premier (EBSCO) and Science Citation Index (ISI). The search phrase "manufacturing knowledge" was used.

Total hits numbered 2921 (January 2007). In the initial search (September 2006) Science Citation Index alone showed 2212 hits (2314 in January 2007). The results were filtered to show only those publications from the year 2001 and later. This narrowed the combined results to 130. A number of the references were then rejected due to the format (generally, only refereed journal papers were included), and in some cases, the availability of the resource. The resource titles and abstracts were initially reviewed to determine appropriate format and content. A more detailed review then took place, to review and categorise the selected papers. A small number of additional papers were included in the review, if they described the fundamentals of a particular domain or framework or if they were considered to add weight to a category. These were generally older references that were outside the search parameters. The papers that were included in the final selection were published in the following years: 1997 (1), 1999 (5), 2000 (1), 2001 (6), 2002 (5), 2003 (5), 2004 (8), 2005 (13), 2006 (30).

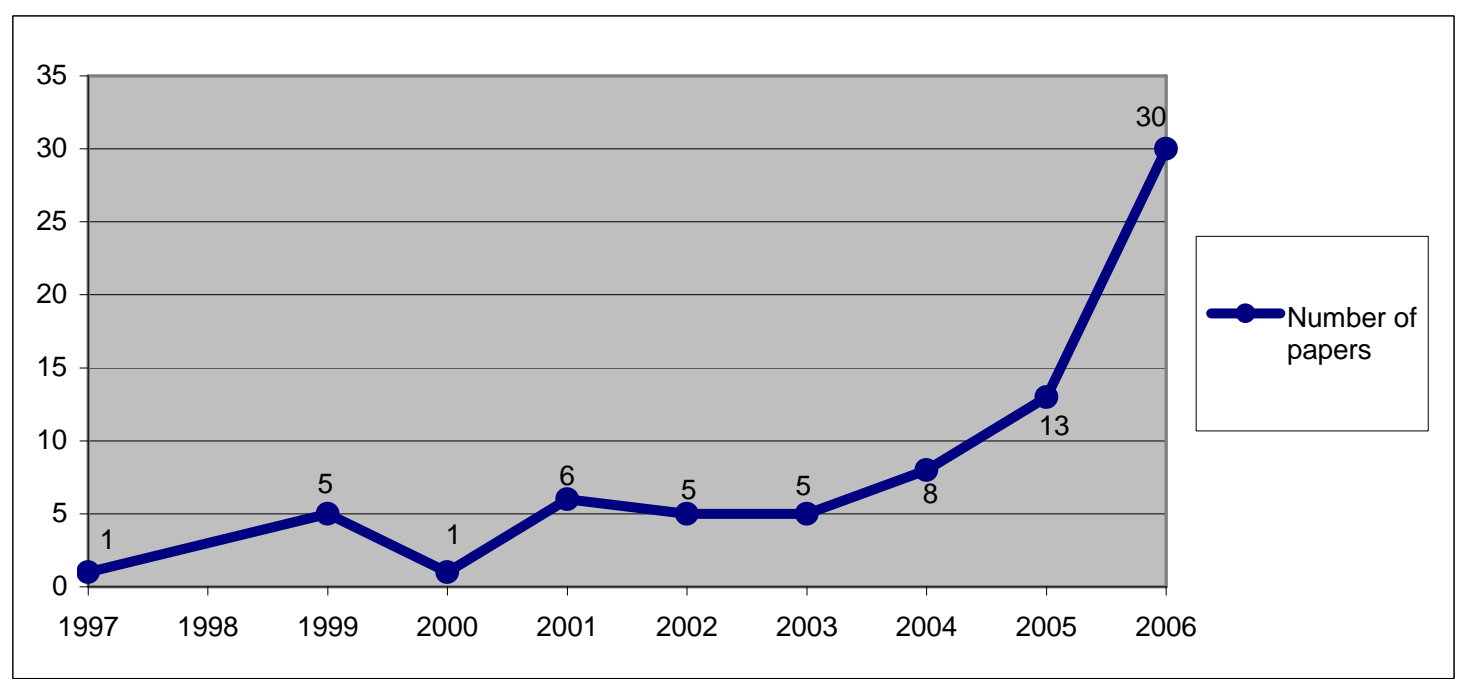

Figure 2: publication years of selected papers

Figure 2 shows a graph of the publication years of the selected papers. Prior to 2001, the papers are not a direct result of the search strategy (these papers were added to enhance the description of certain areas). However, beyond 2001 the graph shows a clearly increasing trend from 2003 to 2006. It is not clear whether this reflects a significant increase in publication in this domain, a change in the terminology used (such as more frequent use of the term 'knowledge') or an unknown bias towards more recent publications in the search strategy. It appears that there has been a 
significant upward trend in publications in the manufacturing knowledge domain since 2003.

The manufacturing knowledge domain is ever advancing, producing research and proposing new methods to better manage and integrate the various elements of the manufacturing domain. This is reflected in the recent increase in publications in the manufacturing knowledge domain. The coordination challenge of the manufacturing enterprise is considerable. Intelligent systems are widespread in the literature. The application of ontology is growing. Knowledge management is a widespread research topic. There are a variety of methods in the research to model and describe the manufacturing domain, including manufacturing models, product models, design and manufacturing process modelling, product features and manufacturing features.

The search method applied produced a relatively homogenous result in terms of the academic specialism behind the research. Virtually all papers are from a manufacturing engineering perspective, with a few notable exceptions. The search method retrieved very few social or management science perspectives on manufacturing knowledge. Engineering design is often considered as an integral part of the manufacturing domain. This is reflected in the subject matter of the papers reviewed.

The research will initially be described from an applications perspective. Knowledge management (including integration, strategy, knowledge mapping, automation and repositories), expert systems (for design analysis, manufacturing analysis), and agent based systems are described. The remaining research is either predominantly focused on a conceptual element or fits well into that category: manufacturing knowledge models, ontology in the manufacturing domain (including fundamentals of ontology and ontology based systems), and information / knowledge structure for design (including feature-based methods, conceptual models, product models and process models). Finally, research relating to service is described.

\section{Concepts and Key Issues in Knowledge management}

Within manufacturing knowledge, several knowledge management (KM) perspectives are described. CEN (Comité Européen de Normalisation, or European committee for standardisation) define knowledge management as:

"Planned and ongoing management of activities and processes for leveraging knowledge to enhance competitiveness through better use and creation of individual and collective knowledge resources." (CEN 2004)

This definition is intentionally broad, covering a range of activities. Within this section, knowledge management is discussed in terms of integration perspective, strategy and implementation, knowledge mapping, automation, and design repositories and knowledge retrieval.

\subsection{Knowledge Integration}

Szyckman et al. discuss IT infrastructure issues presented by next-generation product development; specifically, the need for the integration of knowledge. They suggest that four areas must contribute: software applications, standards, IT infrastructure and 
organisation (Szykman et al., 2001). Schneider and Marquardt describe the life cycle of a chemical process from an information systems integration perspective. They identify the need for systematic consideration and documentation of good practice. They present three life cycle perspectives: workflow, product data, and software, and comment that workflow and product data are often considered independently, where software could be applied as an integrating factor (Schneider \& Marquardt 2002). Wu et al. propose an information framework based on Web services and agent technology to manage product development. Collaborative product development requires coordination of functions and information management across multiple phases (Wu et al., 2004). In each of these proposals, the main objective is integration of the product development activities within a company - the issues of sharing knowledge with external parties has not been addressed. Wu offers the nearest solution, discussing the coordination of "geographically dispersed internal teams and external partners of the product development chain" however while the solution offers distributed coordination at the project level it does not support the intricate aspects of detailed model sharing with external parties at the product level (Wu et al., 2004). It should be noted that their method does offer a practical partial solution, through design parameter consistency checking.

\subsection{Strategy and implementation}

Bohn presents a framework for measuring and understanding technological knowledge - that is, knowledge about how to produce goods and services (Bohn 1997). This is an early example of knowledge management in manufacturing, and is one of the papers included in this review that fell outside the search. It is included as a well cited foundational text that defines many of the issues relating to knowledge management in the manufacturing domain.

Shaw and Edwards propose a method that supports design and negotiation of strategic action plans for manufacturing KM strategy. They apply a workshop method, with a computer based decision support system and a brainstorming software package (Shaw \& Edwards 2006). Wanga studies the implementation of KM in a UK SME. The KM implementation helps the firm (consultants) to generate proposals faster. They can access lessons learned and best practices stored in the repository. The approach is facilitated by IT technologies. A main problem is lack of time to deal with the separate KM system needs (Wonga \& Aspinwall 2006). Honga et al. suggest that as the role of design engineers expands, the clarity of project targets increases. This increases the extent of shared knowledge about customers. Together these factors can enhance productivity. Design engineers are in a position to integrate manufacturing at the conceptual stage because they possess the knowledge to enable it within a cross functional team setting (Honga et al., 2005). Morton et al. developed a management support tool to show the impact of relationships at the boundaries of internal and external activities. The informal network is crucially important in avoiding barriers and delays imposed by the formal structure (Morton et al., 2006). Mapping the informal (social) network is a key feature of the tool. Lu and Botha suggest that manufacturing process development should be viewed as a strategic function for competitive edge, and as such, specific measures should be applied to improve performance. Process design objectives include: product and process quality, smooth and fast ramp-up, cost performance, fast product realisation, and sustainable competitiveness (innovation) (Lu \& Botha 2006). 


\subsection{Knowledge mapping}

Speel et al. suggest that knowledge mapping can create high level knowledge models in a transparent graphical form. As such, knowledge mapping forms a key KM technique. They also suggest that visualisation of relations between knowledge items brings new insights (Speel et al., 1999). Tan and Platts also propose a knowledge mapping approach, based on connectance between concepts. The relationships are stored in a database. The method enables visualisation of how variables interact. The result is similar to a relationship diagram, indicating variables with positive negative relationships (Tan \& Platts 2004). Wang proposes a requirements management method in an automotive scenario. A lack of association between requirements and design makes requirements tracking difficult. The proposed method enables relationships to be captured and tracked by using a matrix. The method is a matrix of matrices, suggesting the use of Axiomatic Design for analysis of some design elements and Design Structure Matrix (DSM) for others (Wang 2006).

\subsection{Knowledge management automation}

Pham and Afify carried out a review of machine learning, which can help to automate knowledge acquisition. Machine learning for very large data sets requires more work, as does machine learning for non-numerical data types such as text and images (Pham \& Afify 2005). Yan demonstrates that a combined knowledge mesh and agent mesh can enable complex knowledge representation for self-reconfiguring complex systems. First order logic relationships are defined (Yan 2006). Koh and Gunasekaran apply a reference architecture to store "tacit knowledge" and apply a software agent to create explicit knowledge. "Tacit knowledge" refers to buffering and dampening techniques. Their proposal is a stock optimisation method using simulation and intelligent agents (Koh \& Gunasekaran 2006).

\subsection{Design repositories and knowledge retrieval}

Alizon et al. developed a search system for design repositories that applies manufacturing information to the search methods, considering similarity, efficiency and configuration (Aifaoui et al., 2006). Shahbaz et al. show that data mining in manufacturing databases can lead to design improvement or fine tuning of production processes. The results of the data mining showed information relating to product geometry and limitations for improvement of existing processes (Shahbaz et al., 2006). Huang and Liang propose a method to retrieve design knowledge through data mining of design databases. Formal modelling of modular products (formulae and production rules) supports the method (Honga et al., 2005). Gardoni et al. present a novel approach to provide manufacturing knowledge to design teams by storing and retrieving text and sketches (Gardoni \& Blanco 2005). Their approach is extended to include semi-structured information (Gardoni et al., 2005).

\section{Knowledge-based intelligent systems}

A range of intelligent systems have been presented in the literature, primarily in the areas of manufacturing analysis and design analysis. There is also a subset of literature that focuses on intelligent systems architecture. In this section, 'intelligent systems' refers to self-defined intelligent systems, expert systems, knowledge-based systems, agent-based systems and optimisation systems. 


\subsection{Design analysis and support systems}

Aziz and Shappasis develop an intelligent system to support gear design. Knowledge bases are used for concept design, detail design, manufacturability evaluation, and manufacturing process design (Aziz \& Chassapis 2005). Harding et al. develop a fuzzy expert system that applies Quality Function Deployment (QFD) type principles to relate customer requirements to product parameters (Harding et al., 2001). Howard and Lewis developed an expert system linked to AutoCAD to provide comparison data on material and process combinations. A material and manufacturing database was incorporated into the system. Process specific rules require analysis of the 3D model to judge suitability of the method. Material properties include mechanical, thermal, electrical and environmental (Howard \& Lewis 2006). Kumara et al. developed an expert system combining AutoCAD and AutoLISP to assess manufacturability of sheet metal parts. Production rules are loaded into AutoCAD, which checks design features against ease of manufacture (Kumara et al., 2006). Shehab and Abdalla developed a knowledge-based system (KBS) to support process cost modelling and design for automation. The system supports the selection of assembly technique, estimates assembly time and cost, and performs analysis of design for automation (Shehab \& Abdalla 2006). Valentincic and Brissaud developed a manufacturing expert system to support design. The system selects an appropriate process for a given product feature. The system also highlights features that are weak from the manufacturing perspective (Valentincic \& Brissaud 2005). Ma applies fuzzy sets and possibility distributions and extends EXPRESS to make it possible to model fuzzy engineering information (Ma 2006). Mok and Wong develop a design evaluation system. They suggest that Feature recognition is "the first prominent stage for any automatic design evaluation system". Their methodology can recognise features of injection moulded parts using a hybrid approach: graph theoretic and logic. Features are classified as: primitive, complex and high level complex (Mok \& Wong 2006). Swift et al. suggest that probabilistic design should be more widely adopted, since deterministic design fails to provide an understanding of the variable nature of manufacture, materials properties and product use (Swift et al., 2001).

\subsection{Manufacturing analysis and support systems}

The distinction between design analysis and manufacturing analysis has a weak basis, since it was stated that design is considered as an integral part of manufacturing; however there are some methods and proposals presented in the literature that are more directly focused on manufacturing (i.e. production) than design. Xie et al. developed a knowledge based decision support system for sheet metal parts. The system includes a design and manufacturing knowledge based module for design support. The system abstracts geometric entities (such as thickness and radius) to support product design and modelling (Xie et al., 2001). Cakir and Cavdar developed a knowledge based system that helps to identify solutions to problems in metal cutting (milling, drilling, turning). The system also provides recommendations for cutting parameters (feed, speed, depth of cut). The problem resolution system uses a "problem, cause and remedy" database (Cakir \& Cavdar 2006). Shakeri develops a combined process planning and tool selection system. The system allows implementation of manufacturing knowledge from an owned facility and from external sites. Previously, operation sequencing and tool selection had been combined into a single optimisation problem, but not implemented in a CAM system (Shakeri 2004). Landryova and Irgens developed a rule-based expert system that combines 
with process monitoring systems to support process management in the oil industry. The aim is to reduce process noise, or variability (Landryova \& Irgens 2006). Liu et al. outline a framework for a STEP-NC controller. The conceptual controller consists of an interpreting module, planning module, simulation module and CNC kernel. The interpreter reads an AP238 file and converts it into internal data, which the planner then applies to the sequencing of machining operations (Liu et al., 2006). Di Stefano proposes a tolerance analysis method that optimises manufacturing costs based on an interaction between customer requirements, design parameters and process variables. This approach takes a holistic, statistical view of the product and applies cost factors from manufacturing tolerances and quality loss (Di Stefano 2006). Vyatkin and Christensen propose a software architecture to support automated production systems. The architecture is composed of software modules called function blocks (Vyatkin \& Christensen 2005). Yongtaoa and Jingying developed a computer aided process planning system, using a features framework to derive manufacturing features and mapping to machining operations. The system generates an optimal process plan based on minimum tool changes and operations (Yongtaoa \& Jingying 2006).

\subsection{Agent based systems}

The research in this section applies software agents to a manufacturing knowledge problem. Feng states that "Agents provide mechanisms to interact with each other" (Feng 2005). This will be applied to a working definition for agents in this context - a software component with a predefined goal and a mechanism to interact with other software components. Balakrishnan et al. define four categories of intelligent information processes: intelligent search, diagnosis and prognosis, collaboration and coordination, and understanding and learning. They suggest that software agents provide an ideal platform for intelligent manufacturing process support (Balakrishnan et al., 1999). Feng developed an integrated conceptual design and process planning method that uses software agents. The method interfaces with a CAD system. Factors such as form, material, tolerance, surface condition, etc. are used in design analysis. This analysis then queries a knowledge base to propose suitable manufacturing processes (Feng 2005). Harding et al. demonstrate the engineering moderator concept. It is an intelligent support tool that uses software agents to aid manufacturing system design by monitoring a design database to detect changes and identify conflicts in order to provide the relevant agent (designer, project manager, etc.) with details of the change and its effects (Harding et al., 2003).

\section{Manufacturing knowledge and information models}

Much of the work cited here on manufacturing information models has been developed within the same group at Loughborough University. Some references that fell outside of the search criteria were added here as they provide a foundation for the work in manufacturing models. Several other references were identified that proposed a manufacturing model, however in the context of this review they were considered more closely related to other sections.

Molina and Bell propose an information model that describes the capability of a manufacturing enterprise. This model supports manufacturing decision making in the concurrent design of products. It is intended to be applied at different levels, to meet the need of a variety of perspectives. The model consists of: Resources, Processes and 
Strategies. The understanding of a manufacturing resource is based on a fundamental hierarchical view: factory, shop, cell, station (Molina \& Bell 1999). Molina and Bell later carried out a review of reference models for supporting engineering. Their resulting proposal combines two methods: CIMOSA (Computer Integrated Manufacturing Open System Architecture) and RM-ODP (Reference Model for Open Distributed Processing). CIMOSA allows the setting of context and requirements of CAE systems in an integrated enterprise. RM-ODP supports the definition of structure and characteristics (enterprise, information, computational, engineering and technology) of CAE systems. The resulting CAE framework is intended to assist in specifying and developing future computer based engineering support systems (Molina \& Bell 2002).

Harding and $\mathrm{Yu}$ develop a factory model, providing information about the capability of the proposed enterprise. Data warehousing contains information about the existing business (timings, inventory, breakdown history). The factory model describes a class structure model (a 'facility' has resource, strategy, process) (Harding \& Yu 1999). Harding and Popplewell propose a factory design software environment, to support design of facilities and processes in parallel with products. The method incorporates a factory data model structure (FDMS), consisting of a set of data classes: process, resource, strategy, facility and token. They demonstrate that a factory model can be progressively populated, providing valuable information to designers (Harding \& Popplewell 1999).

\subsection{Ontology in manufacturing knowledge modelling}

Gruber defines an ontology as an "explicit specification of a conceptualization" (Gruber 1993). A conceptualization is a body of formally represented knowledge; a "simplified view of the world that we wish to represent for some purpose" (Gruber 1993). CEN refer to ontology simply as 'structured terminology' (CEN 2004). Ontology is being applied to formal modelling and reasoning domains, enhancing interoperability.

Ciocoiu et al. suggest that the purpose of ontologies in engineering applications is to make semantics more explicit by providing unambiguous definitions of product and process capabilities. They develop a system to translate from IDEF3 to ILOG via Process Specification Language (PSL - see section 3.7), using ontology descriptions to enable information exchange (Ciocoiu et al., 2001). Nanda et al. suggest that there is a need for a methodology to develop ontologies for design artefacts. They go on to propose a systematic methodology for constructing ontologies to support product family design (Nanda et al., 2006). Crowther et al. assess the suitability of CommonKADS as a methodology to capture knowledge, assessing whether the result is reusable and suitable as the basis for an ontology. They find that the result is not directly suitable for the basis of a domain ontology, but that it serves as a good starting point (Crowther et al., 2003).

Kuczynski et al. suggest that ontologies are a powerful means to store and retrieve knowledge. A single ontology has obvious advantages but is not realistic. Mapping individual ontologies is extensive and cumbersome. A hybrid ontology approach is therefore proposed, using a shared vocabulary (Kuczynski et al., 2006). Qiu developed an information integration framework for the manufacturing enterprise. A domain ontology enables common shared semantics. Three types of integration are 
commonly applied: data, application, and information. A lack of integration leads to incomplete, irrelevant or out of date knowledge bases (Qiu 2006).

Borgo and Leitao ague against the view that general ontologies are unsuitable for real applications. They propose that foundational ontologies, the most general ontologies, have a crucial role to play in building reusable, adaptable and transparent application systems. They demonstrate how they can be used in manufacturing control by adapting a domain specific ontology such that it meets the theoretical organisation requirements of a foundational ontology (Borgo \& Leitao 2004).

Cheeseman et al. developed an agent-based scheduling method incorporating dynamic scheduling to account for breakdown, operator illness and changing priorities. The system is developed using an ontology described using XML (Cheeseman et al., 2005). Cheung et al. demonstrate the application of a knowledge management editor tool to structure organisational knowledge and integrate it with product development. The knowledge editor tool helps to develop an axiom controlled ontology (Cheung et al., 2006). Cochrane et al. develop a method that enables knowledge sharing in manufacturing. They developed a manufacturability analysis platform that applies the PSL ontology as a basis for describing processes (Cochrane et al., 2005). Lin et al. propose an ontology to make the manufacturing system engineering moderator applicable to an extended enterprise through use of shared terms, enhancing semantic interoperability (Lin et al., 2004). Yoshiokaa et al. propose a physical concept ontology to support integration of CAD and CAE at the data level or knowledge level. A functional model maps to a metamodel using physical features. The ontology supports knowledge level modelling for reasoning processes (Yoshiokaa et al., 2004). Lin et al. propose a method for sharing knowledge through use of ontology: maintaining information autonomy through mapping onto a common central ontology, whilst maintaining individual preferences for terminology. The purpose of the system is to support conflict resolution in the design process through change monitoring (Lin et al., 2005). A methodology for developing ontologies is also required (Nanda et al., 2006).

\section{Engineering design knowledge and information models}

Several methods are presented in the research to model products to support distributed design, design model sharing and design analysis. Here they are divided into product data models and design process models.

\subsection{Product data models}

Ma defines the requirements for engineering information modelling in databases and carried out a review to support researchers in the field. Requirements include complex objects and relationships, data exchange and sharing, web-based method, imprecision and uncertainty, and knowledge management. The paper focuses on storage of EXPRESS / STEP conceptual representations (Ma 2005). Aifaoui et al. propose 'mechanical analysis features' as part of a semantically rich product model to support interoperability between design and analysis processes (Aifaoui et al., 2006). Zhang et al. review Internet-based product information sharing and visualisation. They carry out a case study, in which STEP is used to establish a product data master model that 
supports sharing of 3D structures. The objective of the master model is to capture all essential and interrelated information and product properties (Zhang et al., 2004).

Alisanto et al. propose a purpose-behaviour product structure to support collaborative product development. Functional and non functional attributes can be traced to the corresponding product structure elements (Alisantoso et al., 2003). Krishnapillai and Zeid suggest that mass customisation with mass production efficiency requires tight integration of requirements gathering, product design and manufacturing. They propose a methodology to classify design information that can accommodate design variations. Their example applies a design matrix to a simple product design (Krishnapillai \& Zeid 2006). Lee et al. develop a method that supports the requirements collection phase of product modelling by formally defining the terms and grammar that can be used in defining the product model. EXPRESS is applied to the product model. The method formalises product structures and relationships (product has a part is type of part, etc.) (Lee et al., 2006). Ihara and Zhu propose a tree structure to represent design that overcomes problems with sharing manufacturing knowledge transfer across different production cultures. This tree structure is used to generate a process plan. The tree structure provides key product qualities as focus points. This enables the creation of an appropriate plan (Ihara \& Zhu 2003).

Matta et al. present an approach to capture knowledge without disturbing the designer's activities. The approach keeps track of knowledge produced, as a behaviour model linking functions and product structure. Design process modelling is also part of the method, using GRAI nets. This supports the capture of design history (Matta et al., 2002). Wang et al. propose a method to enhance engineering data security management in a peer to peer collaborative environment. Heterogenous design data are exchanged selectively through an XML common interface. Integrated geometric and non-geometric XML data representation using encrypted XML enables sharing of partial models in a secure manner (Wang et al., 2006). Sharing and security are major issues in the manufacturing knowledge domain.

\subsection{Design process models}

Gruninger and Menzel describe the Process Specification Language (PSL). PSL is designed to facilitate exchange of process information among a range of manufacturing systems (scheduling, process modelling, process planning, production planning, simulation...) (Gruninger \& Menzel 2003). Whilst this is not a design process method, the formal representation applied by KIF serves as a good comparison against design process representation approaches. PSL serves as a means to formally describe manufacturing operations. It does not readily support product description.

Krishnan and Ulrich review the literature on product development decisions. They identify four perspectives in product development: engineering design (individualengineer perspective), marketing, operations management (sometimes bridging these perspectives), and organisations (aggregate level) (Krishnan \& Ulrich 2001). The decision perspective helps to identify the support required for design decisions. Lutters et al. describe a method to manage information in engineering processes. They suggest that design and engineering activities need information as input, and that analysing that information is of the utmost importance. If it can be formalised and structured, it can serve as the basis for control of design and manufacturing processes. 
They suggest a structure including product, information and resource (Lutters et al., 2000).

Molina et al. carried out a review on next generation manufacturing systems: reconfigurable and intelligent machines. They suggest that in design of mechatronic systems, development is needed to improve the accuracy and ease of use of simulation tools, and that optimisation methods (mechanics, electronics and software) are still very limited. As such, design requires an integrated development methodology, based on concurrent engineering and life cycle engineering principles. They suggest that product models and manufacturing models could support these activities (Molina et al., 2005). Soares suggests that a simulation tool for production systems can be used to improve organisational structure and to create shared understanding of organisational issues (Soares 2002). This approach requires the creation of formal definitions of the business processes that the manufacturing organisation carries out.

Madhusudan developed an advanced model for information integration and dynamic process management. Three elements are combined: modular software frameworks (Web Services); semantic markup languages; and intelligent process control frameworks. This framework supports product lifecycle management: knowledge regarding products is managed from concept to obsolescence, including process related (how-to) and product related (what-is) knowledge (Madhusudan 2004). Lee et al. developed a data transformation method to enable data from a relational database to be used in a knowledge based system. They propose an XML product data exchange standard, using object principles (polymorphism and inheritance). Previous cases are retrieved through CBR (Lee et al., 2006). Since the proposals are targeted towards product life cycle management, there is a strong emphasis on the process.

\section{Service knowledge}

Daniels and Bryson review aspects of the debate about the distinction between service and manufacturing activities and suggest that it needs to be reconsidered in relation to changes taking place in the production process (Daniels \& Bryson 2002). Service is an increasingly important element of production, and the line between products and services is becoming less clear. In maintenance service, Moore and Starr propose an intelligent system that brings together equipment condition monitor alarms, cost information and risk factors to prioritise maintenance activities (Moore \& Starr 2006). This research demonstrates an intelligent approach to maintenance, integrating a range of knowledge types to support decision making. It does not address service in its wider context or service knowledge in design. The search strategy applied did not provide any papers that consider service knowledge in a design context.

\section{Analysis of research in the manufacturing knowledge domain}

There is a great deal of crossover between the categories presented in the above description of current literature, which was divided largely based on the academic discipline. Several of the papers could have been included in more than one of the selected disciplines. Further analysis will take place to identify the position of the research from two different perspectives: the application domain, and the life cycle stage. The analysis by application domain will show which area of a manufacturing enterprise the research contributes to (focusing here on design and production). The 
analysis by life cycle stage will show where the research contributes according to the stage of the product life cycle.

\subsection{Categorisation of reviewed papers}

The papers were assessed and grouped into categories, with each category representing the target area within a manufacturing enterprise for the proposed solution or method. In this analysis, each paper was only placed into a single category. The categories are shown in Table 1. In order to provide context and a basis for comparison, the categories are represented graphically in Figure 3. The manufacturing enterprise domain

Table 1: categories of reviewed papers

\begin{tabular}{|l|c|}
\hline Category & № papers \\
\hline Information / knowledge structure for design & 17 \\
\hline Expert systems, knowledge-based systems & 11 \\
\hline Ontology in the manufacturing domain & 8 \\
\hline Knowledge management & 7 \\
\hline Knowledge sharing in manufacturing & 7 \\
\hline Enterprise application integration & 5 \\
\hline Manufacturing system (factory) design & 4 \\
\hline Process planning & 3 \\
\hline Production / maintenance scheduling & 3 \\
\hline Role analysis & 3 \\
\hline Other & 6 \\
\hline
\end{tabular}
is divided into two sub-domains: design and production. The categories identified are grouped according to these domains. It can be seen from the figure that 22 of the 74 papers categorised are targeted at the enterprise level. This includes general knowledge management methods, enterprise application integration methods, role analysis techniques and knowledge sharing methods. In the design and production domain, the categories were assigned according to design (25), production (7), and both design and production (14). This analysis highlights a design bias in the manufacturing knowledge domain. The content of each domain is shown in Figure 3.

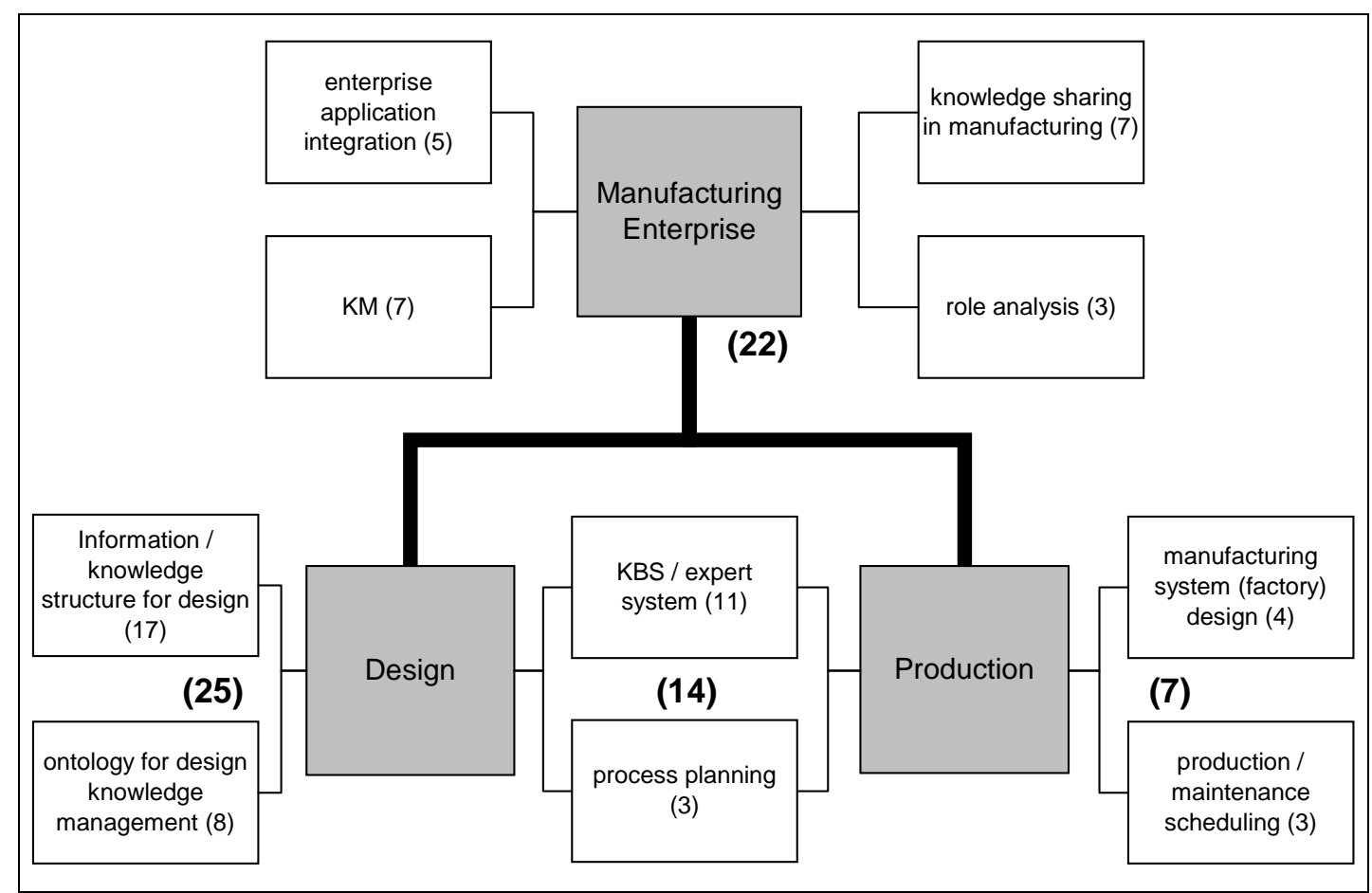

Figure 3: Graphical representation of the papers by categories 


\subsection{Papers addressing different life cycle stages}

Product development is often described in a systematic sense, in which a sequence of activities, or design stages, is defined. A much cited example is developed by Ulrich and Eppinger (Ulrich \& Eppinger 2000), consisting of a sequential model including planning, concept development, system level design, detail design, testing, and production. This view of the NPD process model does not describe the whole product life cycle, since it ends at 'production'. The move towards product life cycle models provides a more complete basis for information and data management, and from that perspective a more complete description of the information and knowledge required during the design stage. A manufacturer's view of a product's life cycle is described by Stark (Stark 2004), in which five stages are proposed: imagine, define, realise, service, and retire. Stark's model adds the dimension of product support (service) and end of life, but it provides very little detail in the product definition stage. The life cycle model presented as part of the CIMOSA modelling framework shows the stages identification, concept, requirements, preliminary design, detailed design, implementation, operation and decommission (Kosanke et al., 1999). This could be argued to be limited in the end of life section according to recent life cycle models "the product life cycle

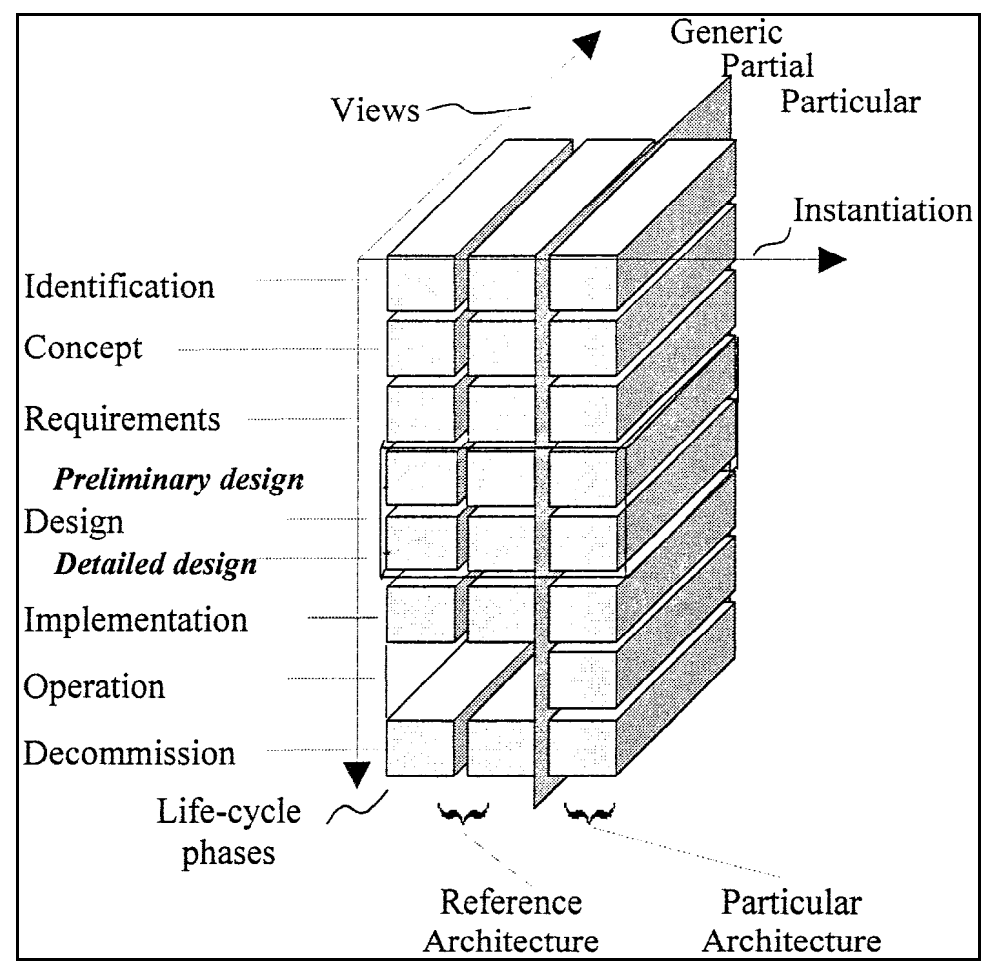

Figure 4: CIMOSA modelling framework (Kosanke et al., 1999) starts with product design, followed by product manufacturing, product servicing and product remanufacturing" (Aurich et al., 2006). The CIMOSA framework will be adopted since it includes multiple design phases and it includes stages in the life cycle beyond the 'use' phase.

The CIMOSA modelling framework shown in Figure 4 has two additional dimensions: instantiation and view. Instantiation refers to the level at which the model is defined:

"Generic enterprise modelling concepts provide means for modelling constructs consistency like language semantic and syntax's definitions through ontologies, formal languages, glossaries, etc. Partial enterprise models provide models which can be reused by modifying enterprise specific attributes of activities and processes... The elements identified in each life-cycle phase of the reference architecture are the building blocks or constructs to be used in the creation of a particular enterprise model." (Kosanke et al., 1999) 
View refers to a method for dividing the model:

"This concept of views allows one to work with subsets of the model rather than with the complete model, providing especially the business user with reduced complexity for his particular area of concern. CIMOSA has defined four different modelling views (Function, Information, Resource and Organisation). However, this set of views may be extended if needed." (Kosanke 1995)

This analysis will show the intended life cycle phase for the proposed manufacturing knowledge methods and the granularity: whether it describes generic modelling concept or a partial enterprise model. Views are not appropriate in this analysis.

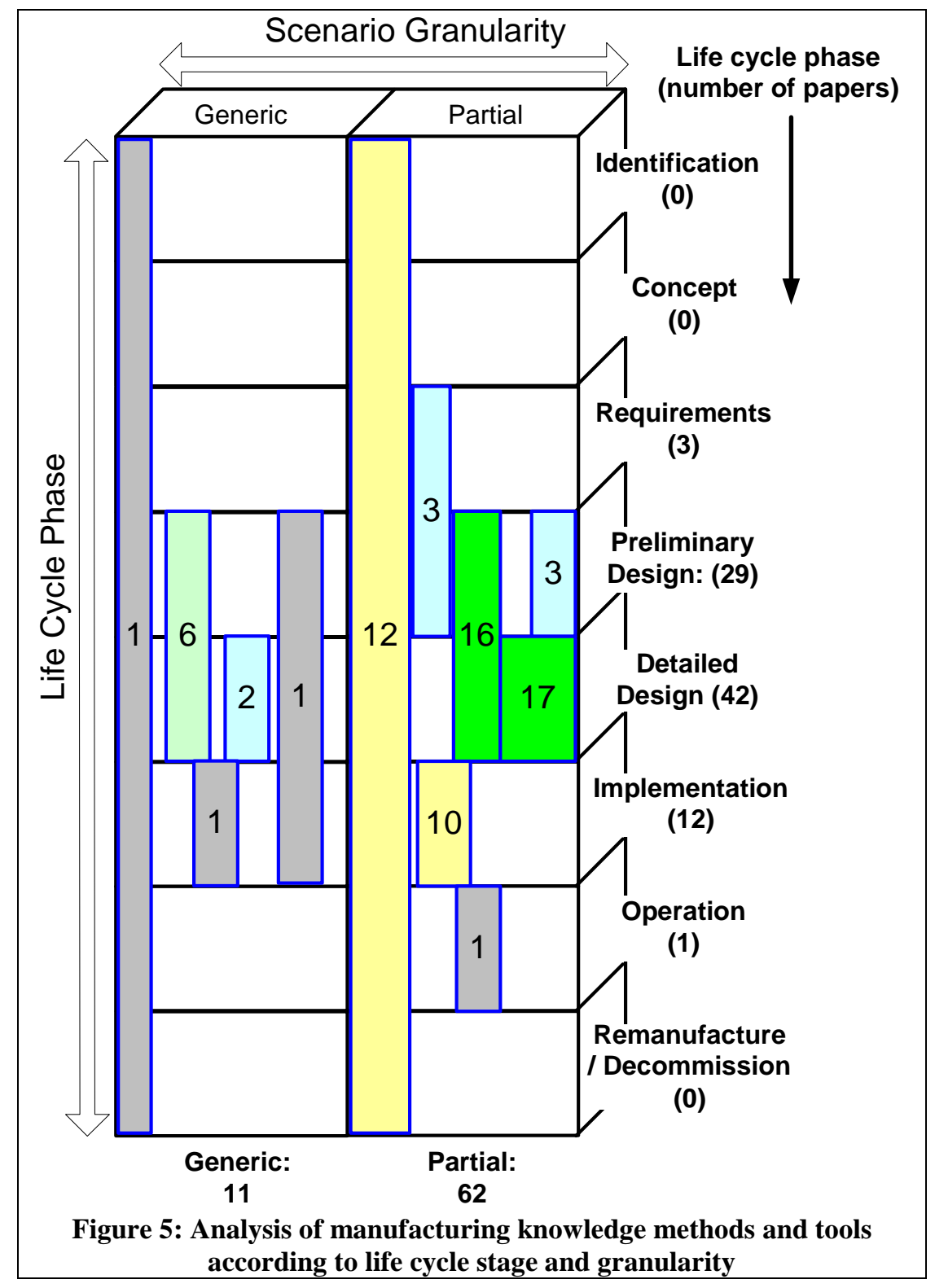

The analysis shows total numbers according to columns (granularity). The numbers shown corresponding to life cycle stage refer to the number of methods and tools that contribute directly to that stage; those which are focused on supporting the particular needs of those activities. This removes the generic knowledge management or enterprise modelling methods that contribute to the whole product life cycle, and 
better reflects where the research focus is relevant to that particular stage of the product life cycle.

The granularity addressed by the manufacturing knowledge research is very much biased towards the 'partial' (models which can be reused by modifying enterprise specific attributes): 62 of the 73 included in the analysis. There is still a clear focus on the generic: 11 of the 73 papers address fundamental research into modelling methods and knowledge and information structures.

The life cycle stage analysis has shown that identification and concept tasks are not addressed in the manufacturing domain. To some extent this is a semantic mismatch; several papers would argue that they address conceptual design, however at this level the work is more closely matched to preliminary design. 3 papers addressed requirements methods - each one integrating requirements and preliminary design. 29 papers focused on preliminary design, 16 of which were also concerned with detail design aspects. 42 papers addressed detailed design, of which 9 related to generic, or fundamental, issues. 12 papers address implementation, or production.

The manufacturing enterprise is described in Figure 3, including the two sub-domains 'design' and 'production'. From that perspective it was shown that there is a design bias in the research. The life cycle analysis in Figure 5 also shows a design bias: a combined total of 47 papers contribute to the preliminary and detailed design phases. Production (implementation) has only 12. This indicates that the recent focus of the manufacturing knowledge domain is significantly biased towards design. The focus on design also indicates that researchers consider the manufacturing domain from an enterprise perspective.

Of the remaining life cycle phases, operation (service) has only 1, and remanufacture / decommission has 0 . Significant growth is expected in this area. The developing research area of product-service-systems (PSS) and a growing demand for end of life management will form a part of the future in this domain. Integration of PSS, design and manufacturing research is expected to follow as the domains mature.

\section{Trends in manufacturing knowledge research}

In this section the categories are compared against publication dates in order to identify trends. In each case, the date range is 2001-2006, to reflect trends identified by the adopted search strategy. The first analysis view compares publication date with category. The categories used are those described in Table 1. The result is shown in Figure 6. 


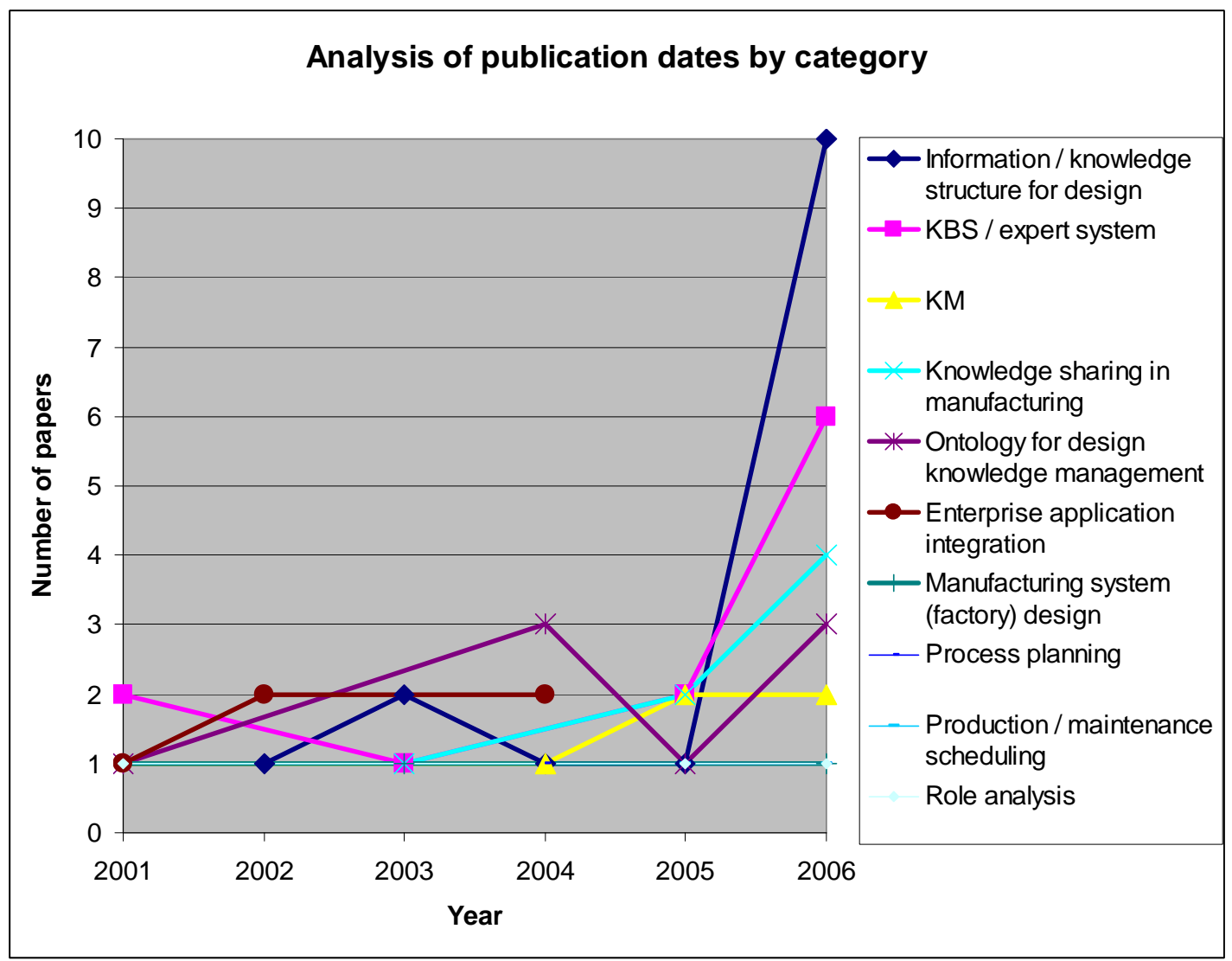

Figure 6: analysis of publication date vs. category

The analysis shows an overall trend similar to the publication pattern in Figure 2: a relatively stable publication rate, increasing significantly in 2006. The largest category growth was seen in information / knowledge structure for design. KBS and expert systems also saw something of a revival, and knowledge sharing in manufacturing also shows significant growth. Even with this growth the knowledge sharing category remains small in 2006 with only 4 papers. 


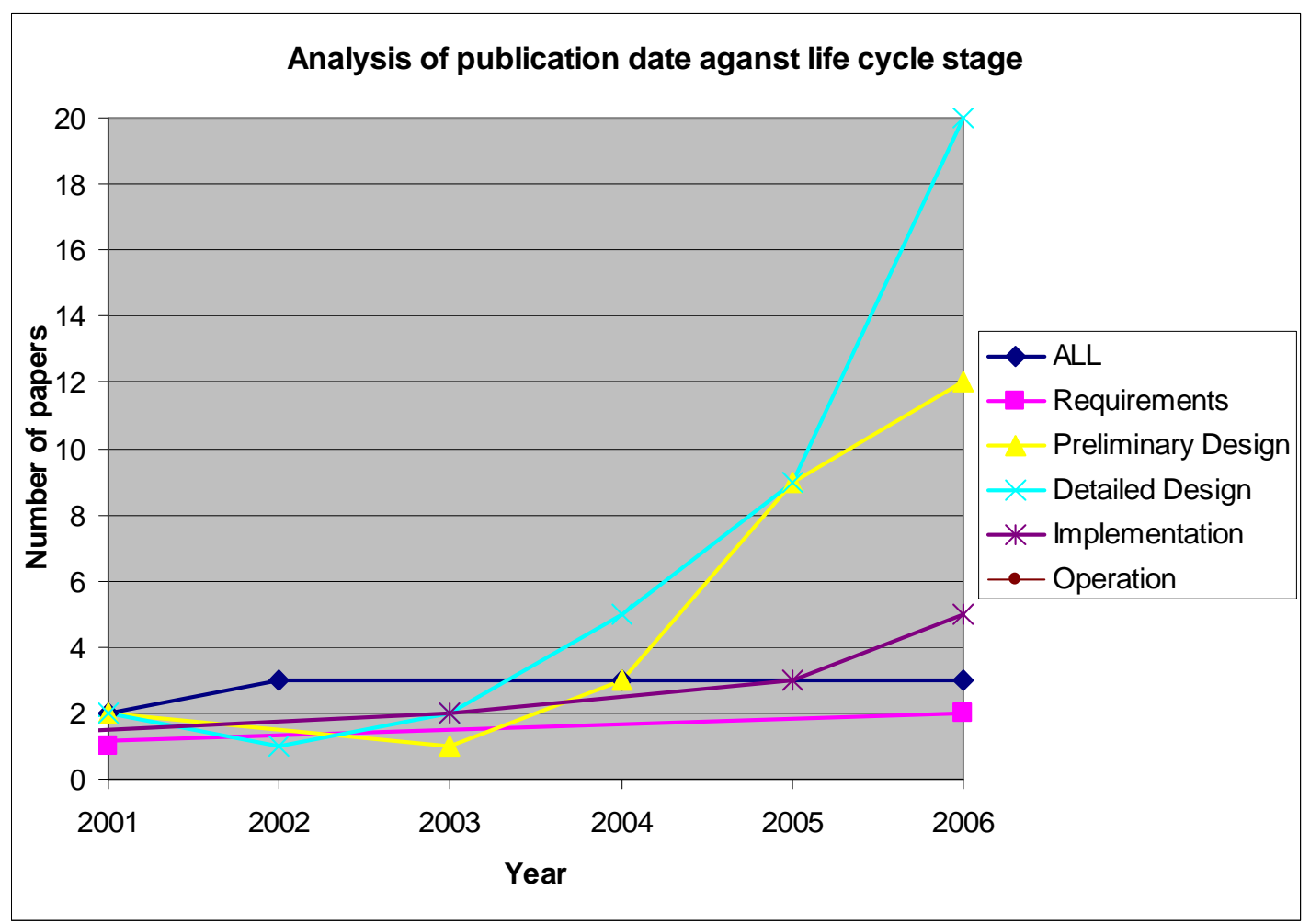

Figure 7: analysis of date vs. life cycle stage

The second analysis view compares publication date against the relevant life cycle stage of the proposed manufacturing knowledge method or system. Again, the general pattern follows a sharp increase in 2005 and 2006. The sharp rise in research focused on detailed design is against expectation according to recent trends in design research, although it is in line with the positioning of manufacturing knowledge as that closest to detailed design in the design life cycle. Preliminary design also sees a sharp rise in the number of publications from 2004-2006. Implementation focused research also sees a modest increase over the period 2004-2006. The other life cycle stages appear stable; the numbers do not increase. 


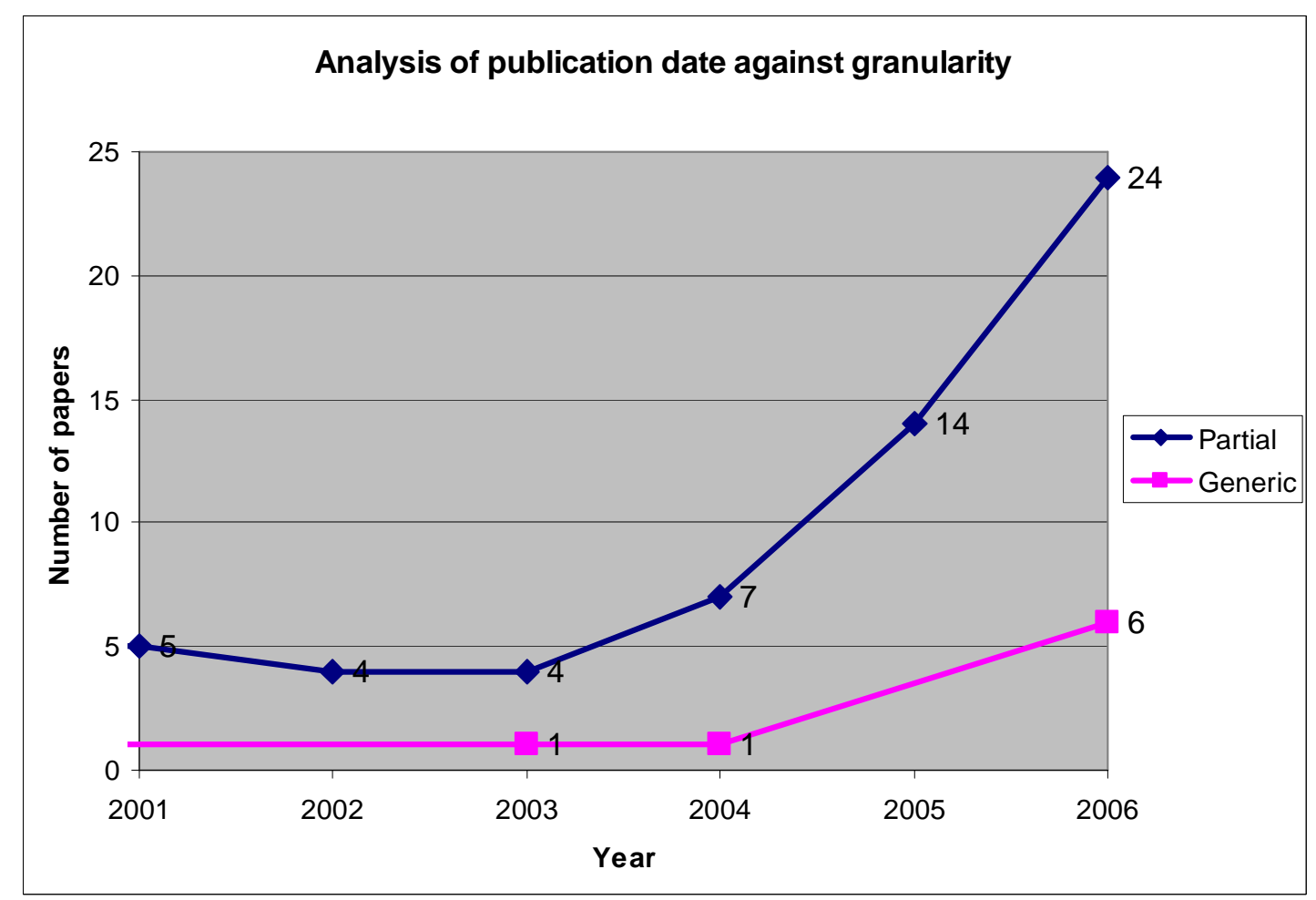

Figure 8: analysis of date vs. granularity

Granularity refers to a spectrum ranging from the theoretical (model constructs) to the practical (implemented system) in enterprise modelling. It has been applied to the analysis of manufacturing knowledge methods and tools to identify whether they represent directly usable methods or foundational concepts. The generic (foundational) level refers to modelling constructs, language semantics and definitions through ontologies, formal languages, and glossaries. The partial level refers to enterprise models that can be reused by modifying enterprise specific attributes.

The analysis shows that the manufacturing knowledge domain is more focused on the application than the underlying modelling constructs and languages: partial level research contributes four times the number of papers in 2006: 24 vs. 6. Both have increased significantly from 2004-2006.

\section{Recommended Future research}

The manufacturing knowledge domain is largely application driven: companies are very much involved in defining the research agenda. Overcoming shortcomings or gaps in current applications forms one stream of research, and the development of future applications forms another stream of research. In both cases, researchers should continue to look to industry in identifying research issues.

The research community has recently increased their recognition of the need for standards and knowledge level integration across the manufacturing enterprise. 'Information and knowledge structures for design' is the category showing the highest growth. This fits with the view of the domain as application driven: integration of manufacturing and design requires the development of information and knowledge structures. This is expected to increase in the near future. In this domain, researchers should collaborate with industry and each other to ensure that the development of 
standards takes account of existing standards as well as industry needs and practices. An interesting growth area for researchers is thought to be more focused on the application of standards than their development: developing methodologies for the adoption and implementation of knowledge level standards, as well as describing case studies with successes or failures of these projects.

KBS and expert systems are also expected to continue their rise, again showing that the research community is driven by applications. In this area, new research should take account of developments in emerging standards and developments in information and knowledge structures.

Focus on the various life cycle stages is expected to continue with the current trends: both preliminary and detailed design will see an increasing amount of focus in the manufacturing knowledge domain. The actual content of the detailed design focus will continue to evolve as the design / manufacturing transfer becomes more knowledge intensive and less resource intensive. Systems are currently commercially available that can generate NC code from CAD models. This closer integration between the design output and manufacturing input is resulting in a change of emphasis in the detailed design phase for manufacturing engineers, and accordingly for the research community. Further work is expected in this area, including knowledge based methods in areas such as design / manufacturing process optimisation, and research applications implementing standards such as STEP-NC.

The long term view of manufacturing knowledge research is an expected shift in focus brought about by an increase in detailed design automation and support. The increasing trend for automation and knowledge level support in the detail design phase will support an increase in preliminary design research. When preliminary design research matures, this will enable the manufacturing knowledge research community to expand beyond preliminary design into the requirements and conceptual design stages. Again, knowledge level support is fundamental in supporting these changes.

In the near term, it is expected that a focus on service will arise. Current developments in product service systems and an increase in full service support packages are creating a need to better integrate design, manufacturing and service operations. The manufacturing knowledge research domain can contribute to this at the knowledge level and at the systems level through defining manufacturing and service activities such that they can interoperate and provide feedback to the design activity. The manufacturing knowledge research community must recognise and embrace the shift towards integrated services to better support integrated product-service design and to support an increase in external services in the manufacturing operation. Alongside service, remanufacture and decommissioning is an area currently lacking in the manufacturing knowledge domain. In order to effectively integrate these activities into the enterprise, particularly design, manufacturing knowledge researchers must develop methods to describe remanufacture and decommissioning of products at the knowledge level. This will support those industries obliged by regulation to take responsibility for their products at the end of life, which includes automotive and white goods. 
From the systems perspective there remain a number of research challenges yet to be addressed. One of those challenges is inter-enterprise communication. The research has a predominantly intra-enterprise focus. A very few of the papers identified by this review describe methods to manage inter-enterprise manufacturing knowledge. This is an area that needs further work.

\section{Conclusions}

The conclusions drawn can be summarised as:

- Manufacturing knowledge research is application driven

- More fundamental research is needed; industry should be included

- There is a clear design bias in the manufacturing knowledge literature

- Detailed design is the focus; preliminary design is growing

- There is a lack of research in the identification and concept stages

- Service research is severely lacking

- Remanufacture and decommissioning research is also severely lacking

The manufacturing knowledge research can be considered from a variety of views: in this review paper the views considered were: academic disciplines, application domain (enterprise view), and life cycle stage. The academic disciplines showed the variety of approaches available to capture, represent and manage knowledge. The enterprise view showed how there is a clear design bias in the manufacturing knowledge literature, although integration between design and production is widespread. The product life cycle view demonstrates a lack of manufacturing knowledge research in the identification and concept stages. This is partly a semantic gap: several of the manufacturing researchers would claim that they are working on conceptual design, whereas they have been classified as preliminary design in this analysis. Service (operation) is clearly under represented in the manufacturing knowledge domain. Service knowledge is of growing importance, particularly in light of the shifting nature of production and service. Implementation (production) also has very little work from the perspective of this review. Manufacturing knowledge integration is lacking in these areas, and represents a research gap. Remanufacture and decommissioning has no work in this domain. Again, this represents a research gap.

\section{Acknowledgements}

The authors would like to acknowledge the support of the EPSRC through Cranfield University IMRC in funding this research. The support of the Decision Engineering centre members in carrying out preliminary reviews of this paper is greatly appreciated.

\section{References}

Aifaoui, N., Deneux, D. \& Soenen, R. (2006) "Feature-based Interoperability between Design and Analysis Processes", Journal of Intelligent Manufacturing, 17 (1) 13-27.

Alisantoso, D., Khoo, L.P., Lee, I.B.H. \& Lu, W.F. (2003) "A design representation scheme for collaborative product development", The International Journal of Advanced Manufacturing Technology, 30 (1-2) 30-39. 
Alizon, F., Shooter, S. \& Simpson, T. (2006) "Reuse of manufacturing knowledge to facilitate platform-based product realization", Journal of Computing and Information Science in Engineering, 6 (2) 170-178.

Aurich, J., Fuchs, C. \& Wagenknecht, C. (2006) "Life cycle oriented design of technical Product-Service Systems", Journal of Cleaner Production, 14 (17) 1480-1494.

Aziz, E.S. \& Chassapis, C. (2005) "A decision-making framework model for design and manufacturing of mechanical transmission system development", Engineering with Computers, 21 (2) 164-176.

Balakrishnan, A., Kumara, S.R.T. \& Sundaresan, S. (1999) "Manufacturing in the Digital Age: Exploiting Information Technologies for Product Realization", Information systems frontiers, 1 (1) 25-50.

Bohn, R.E. (1997) "Measuring and managing technological knowledge", IEEE engineering management review, 25 (4) 77-88.

Borgo, S. \& Leitao, P. (2004) "The Role of Foundational Ontologies in Manufacturing Domain Applications", In: . On the Move to Meaningful Internet Systems 2004: CoopIS, DOA, and ODBASE

Cakir, M.C. \& Cavdar, K. (2006) "Development of a knowledge-based expert system for solving metal cutting problems", Materials \& Design, 27 (10) 1027-1034.

CEN (2004) Knowledge Management: European Standards http://www.cenorm.be/cenorm/businessdomains/businessdomains/isss/cwa/kno wledge+management.asp

Cheeseman, M., Swann, P., Hesketh, G. \& Barnes, S. (2005) "Adaptive manufacturing scheduling: a flexible and configurable agent-based prototype", Production Planning and Control, 16 (5) 479-487.

Cheung, W., Bramall, D., Maropoulos, P., Gao, J. \& Aziz, H. (2006) "Organizational knowledge encapsulation and re-use in collaborative product development", International Journal of Computer Integrated Manufacturing, 19 (7) 736-750.

Ciocoiu, M., Nau, D.S. \& Gruninger, M. (2001) "Ontologies for Integrating Engineering Applications", Journal of Computing and Information Science in Engineering, 1 (1) 12-22.

Cochrane, S., Case, K., Young, R., Harding, J. \& Dani, S. (2005) "Knowledge Sharing Between Design and Manufacture", In: International Conference on Knowledge-Based Intelligent Information and Engineering Systems No9 (KES 2005), Melbourne, Australia 221-227

Crowther, P., Berner, G. \& Williams, R. (2003) "Re-usable knowledge: Development of an object oriented industrial KBS and a collaborative domain ontology", Journal of Intelligent \& Fuzzy Systems, 14 (3) 149-155.

Daniels, P.W. \& Bryson, J.R. (2002) "Manufacturing Services and Servicing Manufacturing: Knowledge-based Cities and Changing Forms of Production", Urban Studies, 39 (5/6) 977-991.

Di Stefano, P. (2006) "Tolerances analysis and cost evaluation for product life cycle", International Journal of Production Research, 44 (10) 1943-1961.

Feng, S.C. (2005) "Preliminary design and manufacturing planning integration using web-based intelligent agents", Journal of Intelligent Manufacturing, 16 (4-5) 423-437.

Gardoni, M. \& Blanco, E. (2005) "MICA-Graph: a tool for managing text and sketches during design processes", Journal of Intelligent Manufacturing, 16 (45) 395-405. 
Gardoni, M., Frank, C. \& Vernadat, F. (2005) "Knowledge capitalisation based on textual and graphical semi-structured and non-structured information", Computers in Industry, 56 (1) 55-69.

Gruber, T. (1993) "A translation approach to portable ontologies", Knowledge Acquisition, 5 (2) 199-220.

Gruninger, M. \& Menzel, C. (2003) "The Process Specification Language (PSL) theory and applications", AI Magazine, 24 (3) 63-75.

Harding, J., Popplewell, K. \& Cook, D. (2003) "Manufacturing system engineering moderator: an aid for multidiscipline project teams", International Journal of Production Research, 41 (9) 1973-1986.

Harding, J., Popplewell, K., Fung, R.Y.K. \& Omar, A.R. (2001) "An intelligent information framework relating customer requirements and product characteristics", Computers in Industry, 44 (1) 51-65.

Harding, J. \& Popplewell, K. (1999) "Information modelling: an integration of views of a manufacturing enterprise", International Journal of Production Research, 37 (12) 2777-2792.

Harding, J. \& Yu, B. (1999) "Information-centred enterprise design supported by a factory data model and data warehousing", Computers in Industry, 40 (1) 23-36.

Honga, P., Vonderembsea, M.A., Dolla, W.J. \& Nahm, A.Y. (2005) "Role change of design engineers in product development", Journal of Operations Management, 24 (1) 63-79.

Howard, L. \& Lewis, H. (2006) "Support tool for material and process combinations during early design", International journal of production research, 44 (17) 3379-3390.

Huang, C. \& Liang, W. (2006) "Explication and sharing of design knowledge through a novel product design approach", IEEE transactions on systems, man, and cybernetics - part c: applications and reviews, 36 (3) 426-438.

Ihara, T. \& Zhu, J. (2003) "The general idea and usage of manufacturing knowledge data-contained differences of production culture", AI \& Society, 17 256-265.

Koh, S. \& Gunasekaran, A. (2006) "A knowledge management approach for managing uncertainty in manufacturing", Industrial Management \& Data Systems, 106 (4) 439-459.

Kosanke, K., Vernadat, F. \& Zelm, M. (1999) "CIMOSA: enterprise engineering and integration", Computers in Industry, 40 (2) 83-97.

Kosanke, K. (1995) "CIMOSA - Overview and status", Computers in Industry, 27 (2) 101-109.

Krishnan, V. \& Ulrich, K.T. (2001) "Product Development Decisions: a review of the literature", Management Science, 47 (1) 1-21.

Krishnapillai, R. \& Zeid, A. (2006) "Mapping Product Design Specification for Mass Customization", Journal of Intelligent Manufacturing, 17 (1) 29-43.

Kuczynski, A., Stokic, D. \& Kirchhoff, U. (2006) "Set-up and maintenance of ontologies for innovation support in extended enterprises", The International Journal of Advanced Manufacturing Technology, 29 (3-4) 398-407.

Kumara, S., Singh, R. \& Sekhon, G. (2006) "CCKBS: A component check knowledge-based system for assessing manufacturability of sheet metal parts", Journal of Materials Processing Technology, 172 (1) 64-69.

Landryova, L. \& Irgens, C. (2006) "Process knowledge generation and knowledge management to support product quality in the process industry by supervisory control and data acquisition (SCADA) open systems", Production Planning and Control, 17 (2) 94-98. 
Lee, C., Ho, G. \& Lau, H.Y., K.M. (2006) "A dynamic information schema for supporting product lifecycle management", Expert Systems with Applications, 31 (1) 30-40.

Lee, G., Eastmana, C.M., Sacks, R. \& Navathe, S.B. (2006) "Grammatical rules for specifying information for automated product data modeling", Advanced engineering informatics, 20 (2) 155-170.

Lin, H., Harding, J. \& Shahbaz, M. (2004) "Manufacturing system engineering ontology for semantic interoperability across extended project teams", International journal of production research, 42 (24) 5099-5118.

Lin, H., Harding, J. \& Teoh, P. (2005) "An inter-enterprise semantic web system to support information autonomy and conflict moderation", Proceedings of the Institution of Mechanical Engineers - Part B - Engineering Manufacture, 219 (12) 903-912.

Liu, R., Zhang, C. \& Newman, S. (2006) "A framework and data processing for interfacing CNC with AP238", International Journal of Computer Integrated Manufacturing, 19 (6) 516-522.

Lu, Q. \& Botha, B. (2006) "Process development: a theoretical framework", International Journal of Production Research, 44 (15) 2977-2996.

Lutters, E., Brinke, E., Streppel, T. \& Kals, H. (2000) "Information management and design \& engineering processes", International Journal of Production Research, 38 (17) 4429-4444.

Ma, Z. (2005) "Engineering information modeling in databases: needs and constructions", Industrial Management \& Data Systems, 105 (7) 900-918.

Ma, Z. (2006) "Extending EXPRESS for Imprecise and Uncertain Engineering Information Modeling", Journal of Intelligent Manufacturing, 17 (1) 57-83.

Madhusudan, T. (2004) "An intelligent mediator-based framework for enterprise application integration", Journal of Computing and Information Science in Engineering, 4 (4) 294-304.

Matta, N., Eynard, B., Roucoules, L. \& Lemercier, M. (2002) "Continuous capitalization of design knowledge", In: Workshop on Semantic Authoring, Annotation and Knowledge Markup, Lyon, France

Mok, C. \& Wong, F. (2006) "Automatic feature recognition for plastic injection moulded part design", The International Journal of Advanced Manufacturing Technology, 27 (11-12) 1058-1070.

Molina, A. \& Bell, R. (1999) "A Manufacturing Model Representation of a Flexible Manufacturing facility", Proceedings of the Institution of Mechanical Engineers, Part B (Journal of Engineering Manufacture), 213 (3) 225-246.

Molina, A. \& Bell, R. (2002) "Reference models for the computer aided support of simultaneous engineering", International Journal of Computer Integrated Manufacturing, 15 (3) 193-213.

Molina, A., Rodriguez, C.A., Ahuett, H., Cortés, J.A., Ramírez, M., Jiménez, G. \& Martinez, S. (2005) "Next-generation manufacturing systems: key research issues in developing and integrating reconfigurable and intelligent machines", International Journal of Computer Integrated Manufacturing, 18 (7) 525-536.

Moore, W. \& Starr, A. (2006) "An intelligent maintenance system for continuous cost-based prioritisation of maintenance activities", Computers in Industry, 57 (6) 595-606.

Morton, S., Dainty, A., Burns, N., Brookes, N. \& Backhouse, C. (2006) "Managing relationships to improve performance: a case study in the global aerospace industry", International journal of production research, 44 (16) 3227-3241. 
Nanda, J., Simpson, T.W., Kumara, S.R.T. \& Shooter, S.B. (2006) "A Methodology for Product Family Ontology Development Using Formal Concept Analysis and Web Ontology Language", Journal of Computing and Information Science in Engineering, 6 (2) 103-113.

Pham, D. \& Afify, A. (2005) "Machine-learning techniques and their applications in manufacturing", Proceedings of the Institution of Mechanical Engineers - Part B - Engineering Manufacture, 219 (5) 395-413.

Qiu, R.G. (2006) "Towards Ontology-driven Knowledge Synthesis for Heterogenous Information Systems", Journal of Intelligent Manufacturing, 17 (1) 99-109.

Schneider, R. \& Marquardt, W. (2002) "Information technology support in the chemical process design life cycle", Chemical engineering science, 57 (10) 1763-1792.

Shahbaz, M., Srinivas, Harding, J. \& Turner, M. (2006) "Product design and manufacturing process improvement using association rules", Proceedings of the Institution of Mechanical Engineers - Part B - Engineering Manufacture, 220 (2) 243-254.

Shakeri, M. (2004) "Implementation of an automated operation planning and optimum operation sequencing and tool selection algorithms", Computers in industry, 54 (3) 223-236.

Shaw, D. \& Edwards, J. (2006) "Manufacturing knowledge management strategy", International Journal of Production Research, 44 (10) 1907-1925.

Shehab, E. \& Abdalla, H. (2006) "A cost-effective knowledge-based reasoning system for design for automation", Proceedings of the Institution of Mechanical Engineers - Part B - Engineering Manufacture, 220 (5)729.

Soares, A.L. (2002) "A tool to support the shared understanding of manufacturing systems organization in innovation processes", International Journal of Computer Integrated Manufacturing, 15 (5) 394-413.

Speel, P.H., Shadbolt, N., Vries, W. d., Dam, P. H. v. and O'Hara, K. (1999) "Knowledge Mapping for Industrial Purposes", In: Proceedings of the Knowledge Acquisition Workshop (KAW 99), University of Calgary, Banff, Canada

Stark, J. (2004) Product Lifecycle Management: 21 st Century Paradigm for Product Realisation. London: Springer-Verlag

Swift, K.G., Raines, M. \& Booker, J.D. (2001) "Advances in probabilistic design: manufacturing knowledge and applications", Proceedings of the Institution of Mechanical Engineers - Part B - Engineering Manufacture, 215 (3) 297-314.

Szykman, S., Sriram, R.D. \& Regli, W.C. (2001) "The role of knowledge in nextgeneration product development systems", Journal of Computing and Information Science in Engineering, 1 (1) 3-11.

Tan, K.-H. \& Platts, K. (2004) "A connectance-based approach for managing manufacturing knowledge", Industrial Management \& Data Systems, 104 (2) 158-168.

Ulrich, K. \& Eppinger, S. (2000) Product design and development. 2 ed. Boston: McGraw-Hill

Valentincic, J. \& Brissaud, D. (2005) "A novel approach to presenting manufacturing knowledge on the design level in toolmaking", Strojniski vestnik - Journal of Mechanical Engineering, 51 (10) 620-633.

Vyatkin, V.\& Christensen, J. (2005) "OOONEIDA: An open, object-oriented knowledge economy for intelligent industrial automation", IEEE transactions on industrial informatics, 1 (1) 4-17. 
Wang, N. (2006) "ERMM: An Engineering Requirements Management Method", Journal of Computing and Information Science in Engineering, 6 (2) 196-199.

Wang, Y., Ajoku, P.N., Brustoloni, J.C. \& Nnaji, B.O. (2006) "Intellectual Property Protection in Collaborative Design through Lean Information Modeling and Sharing", Journal of Computing and Information Science in Engineering, 6 (2) 149-159.

Wonga, K.Y. \& Aspinwall, E. (2006) "Development of a knowledge management initiative and system: A case study", Expert Systems with Applications, 30 (4) 633-641.

Wu, T., Xie, N. \& Blackhurst, J. (2004) "Design and Implementation of a Distributed Information System for Collaborative Product Development", Journal of Computing and Information Science in Engineering, 4 (4) 281-293.

Xie, S.Q., Tu, P.L., Aitchison, D., Dunlop, R. \& Zhou, Z.D. (2001) "A WWW-based integrated product development platform for sheet metal parts intelligent concurrent design and manufacturing", International journal of production research, 39 (17) 3829-3853.

Yan, H. (2006) "A new complicated-knowledge representation approach based on knowledge meshes", IEEE transactions on knowledge and data engineering, 18 (1) 47-62.

Yongtaoa, H. \& Jingying, M. (2006) "A knowledge-based auto-reasoning methodology in hole-machining process planning", Computers in Industry, 57 (4) 297-304.

Yoshiokaa, M., Umedab, Y., Takedac, H., Shimomurad, Y., Nomaguchie, Y.\& Tomiyama, T. (2004) "Physical concept ontology for the knowledge intensive engineering framework", Advanced engineering informatics, 18 (2) 95-113.

Zhang, S., Shen, W. \& Ghenniwa, H. (2004) "A review of Internet-based product information sharing and visualization", Computers in Industry, 54 (1) 1-15. 
Table 2: Domain analysis

\begin{tabular}{|c|c|}
\hline Domain & Reference \\
\hline Information / knowledge structure for design & $\begin{array}{l}\text { Aifaoui, et, al., 2006, Alisantoso, et, al., } \\
\text { 2003, Harding, \&, Yu, 1999, Huang, \&, } \\
\text { Liang, 2006, Krishnapillai, \&, Zeid, 2006, } \\
\text { Alizon, et, al., 2006, Lee, et, al., 2006, Lee, } \\
\text { et, al., 2006, Lutters, et, al., 2000, Ma, 2006, } \\
\text { Ma, 2005, Matta, et, al., 2002, Nanda, et, al., } \\
\text { 2006, Wang, et, al., 2006, Yan, 2006, Zhang, } \\
\text { et, al., 2004, Ihara, \&, Zhu, } 2003\end{array}$ \\
\hline KBS / expert system & $\begin{array}{l}\text { Crowther, et, al., 2003, Di, Stefano, 2006, } \\
\text { Harding, et, al., 2001, Howard, \&, Lewis, } \\
\text { 2006, Kumara, et, al., 2006, Landryova, \&, } \\
\text { Irgens, 2006, Aziz, \&, Chassapis, 2005, } \\
\text { Shehab, \&, Abdalla, 2006, Valentincic, \&, } \\
\text { Brissaud, 2005, Xie, et, al., 2001, Cakir, \&, } \\
\text { Cavdar, 2006 }\end{array}$ \\
\hline KM & $\begin{array}{l}\text { Gardoni, \&, Blanco, 2005, Gardoni, et, al., } \\
\text { 2005, Shaw, \&, Edwards, 2006, Speel, et, al., } \\
\text { 1999, Bohn, 1997, Tan, \&, Platts, 2004, } \\
\text { Wonga, \&, Aspinwall, } 2006\end{array}$ \\
\hline Knowledge sharing in manufacturing & $\begin{array}{l}\text { Cochrane, et, al., 2005, Gruninger, \&, } \\
\text { Menzel, 2003, Liu, et, al., 2006, Mok, \&, } \\
\text { Wong, 2006, Qiu, 2006, Shahbaz, et, al., } \\
\text { 2006, Vyatkin, \&, Christensen, 2005 }\end{array}$ \\
\hline Ontology for design knowledge management & $\begin{array}{l}\text { Cheung, et, al., 2006, Ciocoiu, et, al., 2001, } \\
\text { Kuczynski, et, al., 2006, Lin, et, al., 2004, } \\
\text { Lin, et, al., 2005, Morton, et, al., 2006, } \\
\text { Borgo, \&, Leitao, 2004, Yoshiokaa, et, al., } \\
2004\end{array}$ \\
\hline Enterprise application integration & $\begin{array}{l}\text { Madhusudan, 2004, Molina, \&, Bell, 2002, } \\
\text { Schneider, \&, Marquardt, 2002, Szykman, et, } \\
\text { al., 2001, Wu, et, al., } 2004\end{array}$ \\
\hline Manufacturing system (factory) design & $\begin{array}{l}\text { Harding, \&, Popplewell, 1999, Harding, et, } \\
\text { al., 2003, Lu, \&, Botha, 2006, Molina, \&, } \\
\text { Bell, } 1999\end{array}$ \\
\hline Process planning & $\begin{array}{l}\text { Feng, 2005, Shakeri, 2004, Yongtaoa, \&, } \\
\text { Jingying, } 2006\end{array}$ \\
\hline Production / maintenance scheduling & $\begin{array}{l}\text { Koh, \&, Gunasekaran, 2006, Balakrishnan, } \\
\text { et, al., 1999, Cheeseman, et, al., } 2005\end{array}$ \\
\hline Role analysis & $\begin{array}{l}\text { Honga, et, al., 2005, Krishnan, \&, Ulrich, } \\
\text { 2001, Moore, \&, Starr, } 2006\end{array}$ \\
\hline Other & $\begin{array}{l}\text { Molina, et, al., 2005, Pham, \&, Afify, 2005, } \\
\text { Soares, 2002, Swift, et, al., 2001, Wang, } \\
\text { 2006, Daniels, \&, Bryson, } 2002\end{array}$ \\
\hline
\end{tabular}


Table 3: Life cycle analysis

\begin{tabular}{|c|c|c|}
\hline Life cycle stage & Granularity & Reference \\
\hline ALL & Partial & $\begin{array}{l}\text { Krishnan \& Ulrich 2001, Madhusudan } \\
\text { 2004, Molina \& Bell 2002, Moore \& } \\
\text { Starr 2006, Schneider \& Marquardt } \\
\text { 2002, Shaw \& Edwards 2006, Soares } \\
\text { 2002, Speel et al., 1999, Bohn 1997, } \\
\text { Szykman et al., 2001, Tan \& Platts } \\
\text { 2004, Wonga \& Aspinwall 2006 }\end{array}$ \\
\hline ALL & Generic & Borgo \& Leitao 2004 \\
\hline Requirements; Preliminary Design & Partial & $\begin{array}{l}\text { Harding et al., 2001, Krishnapillai \& } \\
\text { Zeid 2006, Wang 2006 }\end{array}$ \\
\hline Preliminary Design & Partial & $\begin{array}{l}\text { Gardoni \& Blanco 2005, Gardoni et } \\
\text { al., 2005, Alisantoso et al., } 2003\end{array}$ \\
\hline Preliminary Design; Detailed Design & Generic & $\begin{array}{l}\text { Kuczynski et al., 2006, Lee et al., } \\
\text { 2006, Molina \& Bell 1999, Qiu 2006, } \\
\text { Yan 2006, Yoshiokaa et al., } 2004\end{array}$ \\
\hline Preliminary Design; Detailed Design & Partial & $\begin{array}{l}\text { Aifaoui et al., 2006, Cheung et al., } \\
\text { 2006, Cochrane et al., 2005, Di } \\
\text { Stefano 2006, Feng 2005, Honga et } \\
\text { al., 2005, Lin et al., 2004, Lin et al., } \\
\text { 2005, Aziz \& Chassapis 2005, Ma } \\
\text { 2005, Molina et al., 2005, Morton et } \\
\text { al., 2006, Nanda et al., 2006, Swift et } \\
\text { al., 2001, Wang et al., 2006, Wu et } \\
\text { al., 2004 }\end{array}$ \\
\hline $\begin{array}{l}\text { Preliminary Design; Detailed Design, } \\
\text { Implementation }\end{array}$ & Generic & Lutters et al., 2000 \\
\hline Detailed Design & Generic & Lee et al., 2006, Ma 2006 \\
\hline Detailed Design & Partial & $\begin{array}{l}\text { Ciocoiu et al., 2001, Crowther et al., } \\
\text { 2003, Harding \& Popplewell 1999, } \\
\text { Harding et al., 2003, Howard \& } \\
\text { Lewis 2006, Huang \& Liang 2006, } \\
\text { Alizon et al., 2006, Kumara et al., } \\
\text { 2006, Lu \& Botha 2006, Matta et al., } \\
\text { 2002, Mok \& Wong 2006, Shakeri } \\
\text { 2004, Shehab \& Abdalla 2006, } \\
\text { Valentincic \& Brissaud 2005, Xie et } \\
\text { al., 2001, Yongtaoa \& Jingying 2006, } \\
\text { Zhang et al., } 2004\end{array}$ \\
\hline Implementation & Generic & Gruninger \& Menzel 2003 \\
\hline Implementation & Partial & $\begin{array}{l}\text { Harding \& Yu 1999, Koh \& } \\
\text { Gunasekaran 2006, Landryova \& } \\
\text { Irgens 2006, Liu et al., 2006, Pham \& } \\
\text { Afify 2005, Shahbaz et al., 2006, } \\
\text { Ihara \& Zhu 2003, Vyatkin \& } \\
\text { Christensen 2005, Cakir \& Cavdar } \\
\text { 2006, Cheeseman et al., 2005 }\end{array}$ \\
\hline Operation & Partial & Balakrishnan et al., 1999 \\
\hline
\end{tabular}

